\title{
Analysis of Improvement Elements of Walking Environment on Korea Traditional Markets using AHP
}

\author{
Kumho Chung \\ Department of Architecture, \\ Chonnam National University, South Korea \\ kumho@chonnam.ac.kr
}

\section{Abstract}

In this paper we deal with elements for ambulatory improvement to activate traditional markets in South Korea. The object of this study is to analysis the priority of elements of walking space on traditional market using AHP.

This paper used two level hierarchy structure to achieve the object, first level was composited with 4 elements and second level was composited with 28 elements. The questionnaire were made pairwise comparison. The data for analysis was taken through a survey for university students. AHP process leaded the results of this study as follow.

First, the order of element priority is interest, convenience, comfort and safety.

Second, the order of elements to improve traditional markets on Korea are pitchman, street vendors, shopping, price negotiation, paving, landscape, street light, benches, people, bins, street trees, obstacle, information signs, illegal parking, close to the road, nosy, sidewalk width, hustle and bustle, cut off the sidewalk, sidewalk slope, meeting, public transport, traffic, pedestrian, stalls, billboards, vehicle speed, parking lots, humps, and bicycle roads.

\section{Introduction}

\section{Background and propose}

Traditional market is commercial space and is existed by buyer's need. So traditional market is made at the place where is expedient about the meeting and have many walking traffic. Traditional characteristics are on the walking space in traditional markets that has walking, waiting, dealing, shopping and commercial activities. So there are commercial activity and general pedestrian elements (safety, landscape, amenity and convenience) on the walking space ${ }^{1}$ of traditional markets.

It is restoration of the walkability space in traditional markets that is most easily to revitalize economic on downtown where should not be changed the current organization of urban space. Therefore, the characteristics of the traditional market and walking space should be understood to revitalize the traditional market located in the old city center.

Basically this study main goal is the ambulatory to find way for activate traditional markets. The present paper deals the priority of elements to improve elements of walking space on traditional market using AHP.

1 Gardner et al., A report on the development of a pedestrian strategy for London, 1996 


\section{Survey}

This study takes walking improving elements of traditional markets from the already study ${ }^{2}$. A questionnaire was made of 28 elements that were sidewalk width, cut off the sidewalk, illegal parking, obstacle, sidewalk slope, billboards, bicycle roads, speed bumps, street trees, street lights, landscape, pedestrian, close to the road, traffic, the vehicle speed, stalls, paving, benches, bins, information signs, public transport, parking lots, shopping, price negotiation, pitchman, street vendors, people watching, hustle and bustle, meeting and noisy. And these were grouped four groups such as safety, comfort, convenience and interest. It was to find out to identify priority elements of the walking gait improvement. The survey had been on January 10, 2016 on 20 students of Chonnam University in South Korea.

\section{Analysis elements for walking environment on traditional market}

\section{Frame for analysis}

The question was made using hierarchy decomposition, that was divided 4 groups from the result of the already study result was made using pairwise comparison. Those also were used the basis row compassion using the transitivity of preference relation to reduce the numbers of questions.

Table 1 Matrix of pairwise comparison and the basis values

\begin{tabular}{|c|c|c|c|c|c|c|c|c|}
\hline & e1 & e2 & e3 & e4 & e5 & e6 & e7 & e8 \\
\hline e1 & 1 & $\mathrm{x} 1 / \mathrm{x} 2$ & $\mathrm{x} 1 / \mathrm{x} 3$ & $\mathrm{x} 1 / \mathrm{x} 4$ & $\mathrm{x} 1$ & $\mathrm{x} 1 * \mathrm{x} 5$ & $\mathrm{x} 1 * \mathrm{x} 6$ & $\mathrm{x} 1 * \mathrm{x} 7$ \\
\hline e2 & & 1 & $\mathrm{x} 2 / \mathrm{x} 3$ & $\mathrm{x} 2 / \mathrm{x} 4$ & $\mathrm{x} 2$ & $\mathrm{x} 2 * \times 5$ & $\mathrm{x} 2 * \mathrm{x} 6$ & $x 2 * x 7$ \\
\hline e3 & & & 1 & $\mathrm{x} 3 / \mathrm{x} 4$ & $\mathrm{x} 3$ & $x 3 * \times 5$ & $\mathrm{x} 3{ }^{*} \mathrm{x} 6$ & $\mathrm{x} 3 * \mathrm{x} 7$ \\
\hline e4 & & & & 1 & $\mathrm{x} 4$ & $x 4 * x 5$ & $\mathrm{x} 4 * \mathrm{x} 6$ & $x 4 * x 7$ \\
\hline e5 & & & & & 1 & $\times 5$ & $\mathrm{x} 6$ & $x 5 * x 7$ \\
\hline e6 & & & & & & 1 & x6 / x5 & $\mathrm{x} 7$ \\
\hline e7 & & & & & & & 1 & $x 7 / x 6$ \\
\hline e8 & & & & & & & & 1 \\
\hline
\end{tabular}

A question group was made elements took one at random from each 4 groups excepted basis element to verify consistent. Parent group elements were compared completely pairwise. The value from the pairwise comparison about the pedestrian environment elements was made a matrix by each group. And then the priority and the consistency ration were calculated using the AHP process ${ }^{3}$. This calculation process had done by spreadsheet utility Excel. Questionnaire items configured with reference to the previous study and hierarchy is as follows.

Table 2 Hierarchy of walking environment elements on traditional market

\begin{tabular}{lll}
\hline & Level $\mathbf{1}$ & Level $\mathbf{2}$ \\
\hline $\begin{array}{l}\text { Improvement } \\
\text { Elements of Walking }\end{array}$ & Safety & sidewalk width, cut off the sidewalk, illegal parking, obstacle, sidewalk \\
Environment & slope, billboards, bicycle roads, speed bumps \\
& Comfort & street trees, street lights, landscape, pedestrian, close to the road,
\end{tabular}

2 Kumho Chung, Analysis of user satisfaction for walking environment through structural equation modeling at traditional markets, journal of the regional association of architectural institute of Korea, Vol. 14, No. 4, 2012

3 Thomas L. Saaty, Decision making with the analytic hierarchy process, Int. J. Services Sciences, Vol. 1, No. 1,2008 


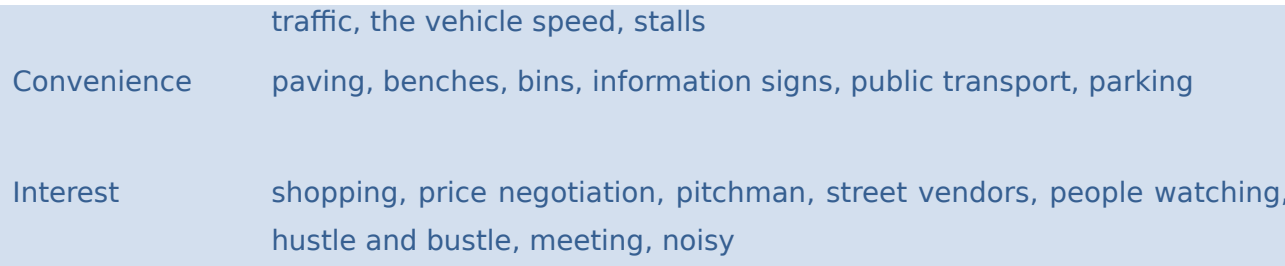

After this the analysis process of AHP as follows;

1 A set of pairwise comparison matrices was constructed each groups (Level 1). Each element in an upper level is used to compare the elements in the level immediately below with respect to it.

2 The priorities obtained from the comparisons used to weigh the priorities in the level immediately below every element. Then for each element in the level below add its weighed values and obtain its overall or global priority.

3 the consistency of the judgments was checked.

4. The results came from this process.

\section{Analysis elements for walking environment on traditional market}

The results of priorities of elements from the AHP process for walking environment on level1 are on the table 3. The order of improvement elements is interest, convenience, comfort and safety. So to activate traditional markets should be upgrade interest.

Table 3 Priorities of element on levell 1 and pairwise comparison matrix

\begin{tabular}{lcrrrr}
\hline & Comfort & Convenience & Interest & Safety & \multicolumn{1}{c}{ Priorities } \\
\hline Comfort & 1.000 & 0.688 & 0.377 & 1.919 & 0.182 \\
Convenience & 1.453 & 1.000 & 0.304 & 1.109 & 0.183 \\
Interest & 2.652 & 3.288 & 1.000 & 3.800 & 0.508 \\
Safety & 0.521 & 0.902 & 0.263 & 1.000 & 0.127 \\
Consistency Ratio & & & 0.027 & & \\
Consistency Index & & & 0.030 & & \\
\hline
\end{tabular}

Table 4 Priorities of element on level 2

\begin{tabular}{clccr}
\hline Elements on Level 1 & Elements on Level 2 & Priorities & $\begin{array}{c}\text { Overall } \\
\text { priorities }\end{array}$ & Order \\
& Sidewalk width & 0.179 & 0.023 & 17 \\
\hline Safety & Cut off the sidewalk & 0.159 & 0.020 & 19 \\
& Illegal parking & 0.193 & 0.025 & 14 \\
& Obstacle & 0.226 & 0.029 & 12 \\
& Sidewalk slope & 0.109 & 0.014 & 20 \\
& Billboards & 0.051 & 0.006 & 26 \\
& Bicycle roads & 0.039 & 0.005 & 30 \\
\hline & Humps & 0.043 & 0.005 & 29 \\
& Consistency Ratio & 0.011 & & \\
& Consistency Index & 0.008 & 0.029 & 11 \\
& Street trees & 0.161 & 0.047 & 6 \\
& Street lights & 0.255 & 0.049 & 24 \\
& Landscape & 0.270 & 0.010 & 15 \\
& Pedestrians & 0.055 & 0.023 & 23
\end{tabular}




\begin{tabular}{|c|c|c|c|c|}
\hline & Vehicle speed & 0.031 & 0.006 & 27 \\
\hline & Stalls & 0.044 & 0.008 & 25 \\
\hline & Consistency Ratio & 0.015 & & \\
\hline & Consistency Index & 0.010 & & \\
\hline \multirow[t]{8}{*}{ Convenience } & Paving & 0.336 & 0.061 & 5 \\
\hline & Benches & 0.252 & 0.046 & 8 \\
\hline & Bins & 0.167 & 0.030 & 10 \\
\hline & Information signs & 0.153 & 0.028 & 13 \\
\hline & Public transport & 0.062 & 0.011 & 22 \\
\hline & Parking lots & 0.030 & 0.006 & 28 \\
\hline & Consistency Ratio & 0.033 & & \\
\hline & Consistency Index & 0.027 & & \\
\hline \multirow[t]{10}{*}{ Interest } & Shopping & 0.163 & 0.083 & 3 \\
\hline & Price negotiation & 0.129 & 0.065 & 4 \\
\hline & Pitchman & 0.296 & 0.151 & 1 \\
\hline & Street vendors & 0.219 & 0.111 & 2 \\
\hline & People watching & 0.084 & 0.043 & 9 \\
\hline & Hustle and bustle & 0.042 & 0.021 & 18 \\
\hline & Meeting & 0.023 & 0.012 & 21 \\
\hline & Nosy & 0.045 & 0.023 & 16 \\
\hline & Consistency Ratio & 0.009 & & \\
\hline & Consistency Index & 0.007 & & \\
\hline
\end{tabular}

The order of elements to improve traditional markets on Korea are pitchman, street vendors, shopping, price negotiation, paving, landscape, street light, benches, people, bins, street trees, obstacle, information signs, illegal parking, close to the road, nosy, sidewalk width, hustle and bustle, cut off the sidewalk, sidewalk slope, meeting, public transport, traffic, pedestrian, stalls, billboards, vehicle speed, parking lots, humps, and bicycle roads. Especially fist order is interest on level 1, but some sub-elements such as people watching, hustle and bustle, meeting and nosy are relatively low on overall order comparing with shopping, price negotiation, pitchman and street vendors. So it is needed more study about the more divided hierarchy model to improve traditional markets on Korea.

\section{Conclusion}

Basically this study mainly deals with the ambulatory to find way for activate traditional markets. The object of this paper is to find the priority of elements to improve elements of walking space on traditional market using AHP. The hierarchy and elements was taken 4 groups, and 28 elements from the already research. The survey, pairwise comparison and the AHP process leaded the results of this paper as follow.

First, the order of element priority is interest, convenience, comfort and safety. So first of all interesting should be upgrade to activate traditional markets.

Second, the order of elements to improve traditional markets on Korea is pitchman, street vendors, shopping, price negotiation, paving, landscape, street light, benches, people, bins, street trees, obstacle, information signs, illegal parking, close to the road, nosy, sidewalk width, hustle and bustle, cut off the sidewalk, sidewalk slope, meeting, public transport, traffic, pedestrian, stalls, billboards, vehicle speed, parking lots, humps, and bicycle roads.

\section{Reference}

Gardner et al., A report on the development of a pedestrian strategy for London, 1996

Kumho Chung, Analysis of user satisfaction for walking environment through structural equation modeling at traditional markets, journal of the regional association of architectural institute of Korea, Vol. 14, No. 4, 
Thomas L. Saaty, Decision making with the analytic hierarchy process, Int. J. Services Sciences, Vol. 1, No. 1,2008

Thomas L. Saaty, L.G. Vargas, The logic of Priorities, Kluwer-Nijhoff Pulishing, 1982

Saaty, Rozann, ed. (2009). "Participant Names and Papers". Proceedings of the 10th International Symposium on the Analytic Hierarchy/Network Process. Pittsburgh, Pennsylvania: ISAHP 